\title{
On the Prevention of Financial Risks in Engineering Projects
}

\author{
Liang Liang
}

\author{
ZiBo Vocational Institute, Accounting College, Zi Bo, Shandong 255314, China \\ Email: 56533939@qq.com
}

\begin{abstract}
To do a good job in financial risk analysis of engineering projects, we should combine the development background of investment projects and the actual development of investment project companies to determine the strategic implementation plan of the company and establish a systematic project operation system. Making reasonable and scientific financial risk analysis, including the company's investment ability and financing ability, can provide reasonable and scientific decision-making basis for project decision-makers and improve the economic benefits of investment projects.
\end{abstract}

Keywords: engineering project, financial risk, prevention

\section{INTRODUCTION}

The occurrence of risk is more and more frequent, so we must do a good job in risk management in order to avoid danger. First, identify the existence of risks according to the actual situation. Second, check whether there is a reasonable and effective risk measurement. The third is to formulate strategies according to the new risks in the process of project construction. Therefore, it is necessary to grasp the risk, prepare risk management plan in advance, formulate feasible specific plan and make full use of relevant resources, and solve the risk according to the actual situation. Our country has adopted four basic policies for the risk management of engineering projects: to control the situation as soon as possible, the key is to take timely actions and control the risk in time; to plan the overall situation well, consider the risk from multiple perspectives, balance the interests of all aspects and maintain their own image to achieve the best results; to grasp the golden period of early decision-making, the main leaders command the decision-making and make rational decision; to establish The rapid response mechanism makes effective use of analytical information. If the company fails in a certain stage or project, the decision-makers of the enterprise should find out and analyze the causes of the failure in time, and provide lessons for the implementation of the operation and management decisions in the future. Strive to realize the combination of theory and practice, reduce the operating cost of the enterprise from the actual situation, and improve the profit of the investment project. It is necessary to collect and sort out data, make scientific and reasonable statistics and analysis of data, calculate or estimate investment costs and expenses of investment projects, and analyze project profitability. When purchasing raw materials, enterprises can actively seek for favorable merchants by strengthening contact with material suppliers and selecting raw materials that can meet their own needs at a lower price. Under the fierce market competition, the project company should actively expand the product market, seize the market opportunity, find the positioning of its own products, establish a good cooperative relationship, and stabilize the company's benefits. This paper describes the characteristics and decision-making methods of risk management from a comprehensive perspective, which provides a basis for the establishment of financial risk management system in China and has certain guiding significance. [1]

\section{FINANCIAL RISK ANALYSIS AND PROBLEMS OF ENGINEERING PROJECT}

The financial risk of engineering project includes many aspects. For tax rate risk, on the one hand, it can be adjusted through the macro direction of national industrial policy, on the other hand, it can also sign agreements with relevant government departments. For inflation risk, it can be included in the statement in advance, and the impact can be reduced by adjusting the accounting statement. In this regard, it is necessary to strictly control the design quality and schedule, select 
competent designers through bidding and other ways, actively cooperate with scientific research institutions, train professional designers, and adopt risk retention and risk transfer methods to avoid delay in the construction period. Establish a good safety management system and supervision system to improve the quality of the project. When dealing with evidence risk, engineering insurance and guarantee can be adopted; when financing engineering projects, domestic and foreign institutions can be introduced to share the risk. On the other hand, we can absorb the nutrition of foreign laws and regulations, sign a series of written agreements with the government to avoid or reduce the risk of changes in policies and regulations, pay attention to national affairs and take preventive measures in advance. According to the results of the uncertainty analysis, we can see the possible risks from project financing, investment and construction, operation and management. For project financing risks, investment project development projects can obtain funds from enterprise self raised capital and financing, among which the loan from the project financing plan to the bank accounts for a large proportion of the total investment. In recent years, China has issued macro adjustment policies, such as bank funds financial institutions are more cautious about loan projects, so the difficulty of project financing plan will increase, which is likely to cause some unpredictable risk factors leading to finance failure. Investment project development project also faces many risks. Different bidding methods of the project lead to the uncertainty of the developers, the changeable environment and weather lead to more accidents, and the uncertain profit and loss of the enterprise due to the uncertainty of labor cost and material cost. [2]

Since the research and implementation of project evaluation started late in China, the state should actively promote the post evaluation of the project, find and solve the problems in time through the results of the post evaluation, and help to combat the improper behaviors in the construction and operation of the project. We can also draw scientific and effective conclusions with the help of changing data. Decision makers don't have all the information about the decision-making situation, so the staff of each institution should pool their ideas and collect information to play a good role as a think tank. At present, China's project risk decision-making is also faced with various constraints, such as time constraints, lack of manpower, information, lack of effective technical support. At present, the problems of financial risk management and control of engineering projects in China mainly include: (1) weak decision-making awareness. We need to pay attention to conventional decision-making, risk decision-making and risk awareness. (2) The risk decision-making body has defects. (3) The quality of decision-makers needs to be improved and the degree of legalization is not high. We are required to optimize the organizational structure, strengthen the think tank, and improve the emergency system and insurance system. (4)
Lack of innovation in decision-making methods Most of the possibility analysis is relatively abstract, rarely demonstrated from a scientific point of view, and few managers really start from the feasibility study report, and ultimately cannot really bring benefits to the enterprise. Therefore, we should improve the innovation ability of decision makers, make innovative decisions, and make decision-making expert and scientific. The project has its own characteristics and particularity, so we should also take appropriate risk response measures. [3]

\section{COUNTERMEASURES AND SUGGESTIONS}

First of all, it should be self raised. Shareholders have certain funds to lay a foundation for the company, so as to facilitate the development of construction, marketing and other businesses. Secondly, we can borrow the power of the society to carry out crowdfunding, private financing and angel financing. We can quickly obtain a lot of funds from the outside, promote the development of the project, and avoid the risk of funds. Then bank loans can be made to meet the requirements of project development and to deal with financing risks. In short, we should adopt multiple channels and financing methods. In project construction, it is faced with the risk of project change, long construction period, cost increase and other risks. In order to avoid the risks in the construction stage, relevant avoidance measures should be taken first when the designer designs the construction scheme. [4]The design scheme should not only ensure the implementation safety of the project, but also consider the economy of the scheme, reduce the waste of funds, save costs, but also ensure the quality of the project. The final project change needs to be approved by the company, and then the change notice can be issued. At the same time, the development and utilization of cost shall be well controlled. The development and construction period of engineering project is long and the cost is high, but if it is longer, the cost will be more increased, which will affect the final profit of the investment project. In the process of investment project implementation and construction, timely obtain new policies in various laws and regulations, improve the anti risk ability of the project, reduce project losses caused by new policies, and ensure the legal compliance of the project. The main risk factors affecting the completion of the investment project include the lack of guarantee of land or other supporting equipment, improper organization and management of the project, and delay of the schedule. [5] The enterprise shall determine the construction progress in time, allocate risks, and ensure the efficient and timely completion of investment projects. With the strengthening of national macro-control, it is more difficult for banks to lend. Enterprises should pay close attention to the changes of the national macroeconomic situation, coordinate the relationship with loan banks, avoid the corresponding policy risks, and increase the proportion of sales returns. 
The company should establish a mature development management team, reduce development risk and make scientific decisions. Enterprises should also strictly follow the project bidding contract, in line with the approval and supervision of the government, otherwise it will affect the development cycle of the project. [6] The occurrence of human cost, raw material cost and some unexpected factors will increase the construction cost of the enterprise, increase the development risk and directly affect the profitability of the project. Therefore, enterprises should actively cooperate with the government, strive for preferential policies within the scope of preferential policies, choose to cooperate with enterprises with good qualifications, reduce the risk; also can seek multiple cooperative enterprises to share the cost risk. Project risk response measures in order to control the risk factor of land development price of investment projects, we need to understand, study and analyze the national land policy thoroughly. A special department can be set up to study and forecast the national land policy. The research and analysis results are more professional, and the impact of the risk factor of land price can also be reduced. Expanding the sales channels is conducive to avoiding the risks in the investment stage of the investment project. The wider the sales channels are, the more flexible the response to the risks is. If an investment project company has only one sales channel of an intermediary company, and the contract expires or other uncontrollable factors hinder the contract, it will cause unsalable investment projects. Therefore, in order to make the investment projects sell, it is necessary to expand the sales channels. We should also do a good job in market demand planning and market research. Make a good marketing plan, select multiple sales channels, and improve the sales feasibility of the project. With the strengthening of national macro-control, it is more difficult for banks to lend. Enterprises should pay close attention to the changes of the national macroeconomic situation, coordinate the relationship with loan banks, avoid the corresponding policy risks, and increase the proportion of sales returns. The company should establish a mature development management team, reduce development risk and make scientific decisions. Enterprises should also strictly follow the project bidding contract, in line with the approval and supervision of the government, otherwise it will affect the development cycle of the project. [7] The occurrence of human cost, raw material cost and some unexpected factors will increase the construction cost of the enterprise, increase the development risk and directly affect the profitability of the project. [8] Therefore, enterprises should actively cooperate with the government, strive for preferential policies within the scope of preferential policies, choose to cooperate with enterprises with good qualifications, reduce the risk; also can seek multiple cooperative enterprises to share the cost risk. In the period of risk recovery, we need to learn from the organizational risk lessons, timely change the organization, and in-depth reflection on it. Build and improve the decision-making mechanism in the risk state, even if the non procedural risk decision-making is procedural, patterned and statutory. We will continue to improve the construction and improvement of risk decision-making mechanism, improve decision-making ability and efficiency, and improve management level, so as to reduce risks and promote the normal operation of the project. [9]

There are two main reasons for the impact of financial crisis, internal causes and external environment on enterprises

\section{Internal causes of financial crisis}

There are three main reasons for the financial crisis, that is, the construction of enterprise financial construction is unreasonable, the enterprise financial management is not scientific enough, and the enterprise capital recovery is difficult. The unreasonable financial construction of enterprises is mainly due to unscientific capital investment and capital transfer. According to the survey, $70 \%$ of enterprises are debt management. The use of funds by enterprises will not reduce the efficiency of capital investment, and the serious reasons of capital turnover can not work. The main task of enterprise financial management is to calculate the assets of enterprises, which is very beneficial to the reasonable planning of enterprise assets. Therefore, the problems of enterprise asset management will aggravate the asset status of the enterprise and cause the financial crisis of the enterprise. If the foreign investment fund of an enterprise cannot be recovered within the predetermined time, it will affect the capital transfer of the enterprise and trigger the financial crisis.

External environment changes caused by enterprise financial crisis

Once the international exchange rate drops, the number of foreign-funded enterprises will decrease, and then cause financial crisis. The market environment is mainly affected by the financial crisis caused by the enterprise material procurement costs and goods sales. The rise of material market price will greatly increase the investment cost, resulting in low enterprise income. The change of legal environment is mainly related to the promulgation of relevant laws.

\section{CONCLUSION}

\subsection{Guard against enterprise financing risk}

The main risk of enterprise financing is that the enterprise can't repay the foreign debt. Therefore, the prevention of financing risk is mainly the control of enterprise debt repayment ability. Enterprises should always grasp the three indicators of debt repayment ability and analyze the optimal flow ratio according to the specific situation of the enterprise. The enterprise must 
first formulate the optimal flow ratio according to its own situation. Then, the enterprise should strictly control the flow, and the flow fluctuation should take timely measures to prevent the occurrence of financing risks, so as to prevent the occurrence of financial crisis.

\subsection{Enterprise investment risk control}

When the normal operation of the enterprise investment is necessary, but if the enterprise investment will not only affect the economic benefits of the enterprise, serious may also lead to financial crisis. Enterprise investment risk assessment can provide scientific basis for enterprise investment. Therefore, the investment risk assessment of enterprises should not only be done, but also carried out with high quality. Only by providing a more scientific reference basis for enterprise investment, can we control the risk of enterprise investment, thus reducing the investment caused by economic loss of investment, so as to prevent the outbreak of enterprise financial crisis.

\subsection{Tax risk control of enterprises}

Establish a series of internal control mechanism of tax risk, formulate a series of self-discipline systems and procedures of tax risk management, implement effective tax management, comprehensive and systematic, implement dynamic management of tax risk, timely identify, and evaluate the changes of original and new risks according to the evaluation results, and fully consider the cost-effectiveness of risk management, the overall management and control system, We should formulate tax risk coping strategies, reasonably design tax management process and control methods, and control tax risk.

\subsection{Enterprise tax information management}

Establish a tax risk management information exchange system, clarify the tax information collection, processing and delivery procedures, ensure the company's tax department, enterprise tax department and other departments, enterprise tax department, board of directors, board of supervisors and other corporate governance and management communication and feedback, timely issue problems and timely report and take action.

\section{ACKNOWLEDGMENT}

This work was supported by Shandong Province education science "13th Five-Year plan" project (byzn201915) funding.

\section{REFERENCES}

[1] Y. Liu, Z. Y. Zhu, Discussion on financial risks and Countermeasures of PPP project of the company [J]. Financial accounting study, 2019, (17): 46-47

[2] J. H.Huang, Analysis of financial risk control of PPP project $[\mathrm{J}]$. Contemporary accounting, 2019, (2): $45-46$

[3] M. Y. Li, Financial risk of construction enterprise project

[4] Andrey Volkov, Dries F. Benoit, Dirk Van den Poel Incorporating sequential information in bankruptcy prediction with predictors based on Markov for discrimination[J] Decision Support Systems, 2017, 98

[5] Philippe du Jardin A two-stage classification technique for bankruptcy prediction[J] European Journal of Operational Research, 2016, 254(1)

[6] K.C. Wong, S.C.P. Yam, J. Zeng Mean-risk portfolio management with bankruptcy prohibition[J] Insurance Mathematics and Economics, 2019

[7] Maciej Zięba, Sebastian K. Tomczak, Jakub M. Tomczak Ensemble boosted trees with synthetic features generation in application to bankruptcy prediction[J] Expert Systems With Applications, 2016, 58

[8] Tuong Le, Bay Vo, Hamido Fujita et al. A fast and accurate approach for bankruptcy forecasting using squared logistics loss with GPU-based extreme gradient boosting[J] Information Sciences, 2019 , 494

[9] J. Arin, J. Benito-Ostolaza, E. Inarra The reverse Talmud family of rules for bankruptcy Problems: A characterization $[\mathrm{J}]$ Mathematical Social Sciences, 2017, 89 